\title{
A GAME THEORY APPROACH TO SALINIZATION PROBLEM OF THE ARAL SEA BASIN
}

\author{
AKHMEDJONOV, A. $^{1}{ }^{*}-$ SUYUNDIKOV, A. $^{2}$ \\ ${ }^{1}$ Assistant Professor of Economics, Zirve University \\ Gaziantep 27260 Turkey \\ (phone: +90-342-211-6666 ext. 6846) \\ ${ }^{2}$ Department of Statistics, Utah State University \\ 1400 Old Main Hill, Logan 84322 Utah, USA \\ (phone: +1-435-797-0017) \\ *Corresponding author \\ e-mail: alisherakhmedjonov@zirve.edu.tr \\ (Received $1^{\text {st }}$ April 2011; accepted $2^{\text {nd }}$ December 2011)
}

\begin{abstract}
This paper studies a transboundary economy with two countries located in a lake basin. Each country withdraws water from the lake for irrigation purposes, which in turn causes the lake to desiccate. The receding lake leaves surfaces covered with salt dust, which is transported by wind to the surrounding area, increasing the salinity of the two countries' lands. This paper examines whether a partially cooperative water - allocation scheme, where a central authority chooses the two countries' respective abatement levels (of salt dust) after the countries individually choose per-unit taxes on water withdrawal, induces the countries to withdraw water at the socially efficient level. We find that the partial scheme works, i.e. it induces both countries to optimally choose to withdraw at the socially efficient level.
\end{abstract}

Keywords: interbasin water resources allocation, water quality, benefit reallocation, optimization, game theory

\section{Introduction}

The problem of optimal water use in international river basins has become a major concern. There are more than 200 river basins in the world that are shared by two or more countries (WRI, 2000). Rapid population and economic growth, increasing prices for food and other commodities, and the scarcity of water resources make water consumption a key issue in international river basins. According to the World Resource Institute (2000), roughly 3.5 billion people world wide are expected to live in waterstressed river basins by 2025 .

Inefficient water use by riparian countries not only causes hydropolitical conflicts, but also compromises the socio-economic and environmental sustainability of the countries' water basins. For example, the Aral Sea (formerly one of the four largest lakes of the world, with an area of 68,000 square kilometres (26,000 sq mi)), has been steadily shrinking since the 1960s, after the rivers feeding it were diverted by Soviet Union irrigation projects (Micklin and Aladin, 2008). The Soviet Union pursued cotton production on a massive scale in the Aral Sea basin. As a result, Uzbekistan is now the world's sixth-largest producer and second-largest exporter of cotton (Cotton This Week, 2005). However, the drying sea has destroyed marine, coastal and delta ecosystems, altered the local climate, increased salination of crop lands, and compromised the livelihoods of hundreds of thousands of people. A lack of fresh water and extremely polluted air has turned the Aral Sea basin into an ecologic disaster zone, with an 
accelerated rate of health problems (Godwin, 2003). The receding sea has left huge plains covered with salt and toxic chemicals - the results of weapons testing, industrial projects, pesticides and fertilizer runoff - which are picked up and carried away by the wind as toxic dust and spread throughout the surrounding area (Mangold and Goldberg, 2001). For example, wind-blown sand and salt production in the dried Aral seabed area on average reaches 40-45 million tons per year. The main dust and salt transport processes occur within $300 \mathrm{~km}$ of the coastal lands. Annual volumes of dust emission into the atmosphere from the dried Aral seabed area amount to 15-75 million tons, which has an adverse effect on irrigated farming (Mangold and Goldberg, 2001).

Several studies have estimated the environmental impact of cotton irrigation on the Aral Sea basin's water resources. Gillham (1995) asserts that cotton production requires heavy application of agricultural chemicals, which pollute freshwater ecosystems with nutrients, salts and pesticides. Gillham also classifies water withdrawal for extensive irrigation as one of the mechanisms by which cotton production impacts rivers, lakes and wetlands. He examines surface salination of the depleted Aral Sea in particular, which is the most severe consequence of extensive water withdrawal. In Uzbekistan, for example, $50 \%$ of the irrigated area is affected by salinity.

A number of economic studies show that a cooperative water - resource allocation would lead to reduction in total water withdrawal for irrigation purposes in international river and lake basins. For example, Rogers (1969) formulates a cooperative game of water allocation for the Ganges and Nile rivers and shows how cooperation leads to a Pareto efficient allocation. Hardin (1968) provides an explanation of the "tragedy of the commons", which explains why water resources are sometimes heavily overexploited because of noncooperation among competing users. In a noncooperative setting, the resulting Nash equilibrium leads the riparian countries to exploit water resources in a noncontrolled and unregulated fashion. Moulin (1995) demonstrates that aggregate water use under full cooperation is generally smaller than under noncooperation when general conditions are met.

In this paper, we examine whether a partially cooperative water allocation scheme can reduce the level of salination in a river basin such as the Aral Sea basin. By "partially cooperative" we mean that the national governments and a separate central authority share policy instruments in such a way that the national governments choose on their own the socially-efficient salination levels. In this regard, the acid rain model developed by Caplan and Silva (1999) is particularly relevant. Following their work, we consider a model where two countries withdraw water from a lake for irrigation purposes. Water withdrawal causes the lake to desiccate; desiccation that extends to adjacent areas by increasing the salination of irrigated lands in both countries. In contrast with Caplan and Silva (1999), we assume both countries are "downwinders" in the sense that a country's water withdrawal not only affects its own national environment, but that of its neighbor (in Caplan and Silva, 1999), one of the countries' emissions affected solely itself (downwind country), while the other's emissions affected both itself and the other country (upwind country)). In particular, we investigate "decentralized leadership" regime, where a central authority chooses the two countries' respective abatement levels (of spit dust) after the countries individually choose per - unit taxes on water withdrawal. As in Caplan and Silva (1999), we find that this regime leads to a socially efficient water allocation. 


\section{Model}

Following Caplan and Silva (1999), we consider an economy in which two countries exist in a lake basin. The countries, indexed by $i, i=1,2$, withdraw water from the lake for irrigation purposes. There are two private goods, $x$ and $y$ : good $x$ is a numeraire and $y$ is "cotton". We further assume that each country has an identical cotton production technology. Each country withdraws water from the lake to maximize their own economic benefit from cotton production, which causes the lake to desiccate. The desiccating lake leaves surfaces covered with salt, which in turn is transported by the wind as dust that spreads to surrounding areas.

We assume that country $i$ produces $Y_{i}$ units of cotton and consequently $Y_{i}$ units of salt. However, the country can adopt a more efficient irrigation system and drip watering in cotton cultivation that reduces the dessication of the lake, and thus decreases its contribution to salination. If country $i$ produces $Y_{i}$ units of cotton and reduces salt emission by $a_{i}$ units, through adoption of a new thechnology, the level of salt dust ultimately emitted is $E_{i}=Y_{i}-a_{i}, i=1,2$. Capacity levels for cotton production and salt abatement are denoted as $Y_{c}$ and $a_{c}$, respectively. These levels are sufficiently high enough to never be reached.

We denote the level of damage in country $i$ from salination as $D_{i}$, defined as:

$$
D_{i} \equiv \alpha_{i} E_{i}+\left(1-\alpha_{j}\right) E_{j} \equiv \alpha_{i}\left(Y_{i}-a_{i}\right)+\left(1-\alpha_{j}\right)\left(Y_{j}-a_{j}\right), i, j=1,2
$$

where $\alpha_{i}$ and $\alpha_{j}$ are the fractions of salt dust that damage countries $i$ and $j$, respectively. The remaining fractions, $\left(1-\alpha_{i}\right)$ and $\left(1-\alpha_{j}\right)$ are the fractions of salt dust emitted in countries $i$ and $j$ that affect countries $j$ and $i$, respectively. As a result, $\left(1-\alpha_{1}\right) E_{1}$ and $\left(1-\alpha_{2}\right) E_{2}$ are the tranboundary damages affecting countries 2 and 1 , respectively.

As in Caplan and Silva (1999), we assume $n$ residents reside in each country, which for simplicity we normalize to 1 . An individual who resides in country $i$ derives the following welfare from consumption of $x_{i}, y_{i}$, and $D_{i}$ :

$$
W_{i}=x_{i}+u\left(y_{i}\right)-v\left(D_{i}\right), \quad i=1,2
$$

where $u$ is increasing and strictly concave and $v$ is increasing and strictly convex. Assume numeraire good $x_{i}$ is used for consumption and as an input in the production of cotton and dust abatement in each country. The total cost of cotton and abatement production in country $i$ can therefore be written as:

$$
K+p Y_{i}+s a_{i}, \quad i=1,2
$$

where $K>0$ is a fixed cost, $p>0$ is the cost per unit of cotton produced, and $s>0$ is the cost per unit of salt dust abatement produced. In equilibrium country i's cotton supply is its demand; namely, $Y_{i}=y_{i}$. Country i provides its consumers with cotton at 
per - unit price $p+t_{i}$, where the excess of the price over marginal cost, ${ }^{t}$, represents a per - unit pollution tax. Each resident of country $i$ is imposed a head tax in the amount of $K+s a_{i}$ that compensates both the fixed and abatement components of total production cost. The revenue collected from the per-unit pollution tax in country $\mathrm{i}$ is returned to this country's residents as a lump-sum payment $r_{i}=t_{i} y_{i}, i=1,2$.

Thus, the budget constraint for the representative resident of country $i$ can be written as:

$$
x_{i}+\left(p+t_{i}\right) y_{i}+K+s a_{i}=I+r_{i}, \quad i=1,2
$$

where, for each $i$, the left-hand side of (3) shows the representative resident's total expenditure and the right-hand side of (3) gives his total income (income $I$ plus the lump-sum tax revenue $r_{i}$ ).

\section{Consumers' maximization problems}

In this section we examine the maximization problems of consumers (residents) in order to calculate how residents respond to the policy choices introduced by the governments of both countries, as well as the choices of a central authority. Thus, a resident in country $i$ chooses $\left\{x_{i}, y_{i}\right\}$ to maximize utility (2) subject to his/ her budget constraint (3), taking as given governmental policy variables and the overall level of salination. The solutions to the individuals' optimization problems are:

$$
\begin{gathered}
x_{i}=I-p y_{i}-K-s a_{i}, i=1,2 \\
u^{\prime}\left(y_{i}\right)=p+t_{i}, i=1,2
\end{gathered}
$$

where equation (4) is derived from equation (3) using the equality $r_{i} \equiv t_{i} y_{i}$, for all $t_{i} \geq 0, \mathrm{i}=1,2$. Equation (5) is the typical first - order condition where the marginal rate of substitution, $u^{\prime}\left(y_{i}\right)$, equals relative prices, $p+t_{i}$ (recall that $x_{i}$ is a numeraire good, with price equal to 1). For each i, equations (4) and (5) define $x_{i}$ and $y_{i}$ as implicit functions of $t_{i}, a_{i}, p, s, I$ and $K$, denoted $x_{i}^{0}$ and $y_{i}^{0}$. Note that $y_{i}^{0}$ does not depend on $a_{i}$ from equation (5). We can therefore define the individual's demand functions as $x_{i}^{0} \equiv x_{i}^{0}\left(t_{i}, a_{i}\right)$ and $y_{i}^{0} \equiv y_{i}^{0}\left(t_{i}\right)$.

The individuals' responses to changes in the governmental policy variables are the same as in Caplan and Silva (1999):

$$
\frac{\partial x_{i}^{0}}{\partial t_{i}}=-p \frac{\partial y_{i}^{0}}{\partial t_{i}}=-\frac{p}{u^{\prime \prime}\left(y_{i}^{0}\right)}>0, \quad i=1,2
$$




$$
\frac{\partial x_{i}^{0}}{\partial a_{i}}=-s<0, \quad i=1,2
$$

Here we can see that equations (6) and (7) are a strightforward implication of the implicit function theorem. We assume that in a subgame perfect Stackelberg Equilibrium the governments and the central authority know the consumers' response functions (6) and (7) when choosing their environmental policies.

\section{Noncooperative benchmark equilibrium}

In the case of noncooperative water allocations, each country concerns itself with maximizing its own utility. Therefore, country 1 chooses $\left\{t_{1}, a_{1}\right\}$ to maximize

$W_{1}\left(t_{1}, t_{2}, a_{1}, a_{2}\right)=x_{1}^{0}\left(t_{1}, a_{1}\right)+u\left(y_{1}^{0}\left(t_{1}\right)\right)-v\left(\alpha_{1}\left(y_{1}^{0}\left(t_{1}\right)-a_{1}\right)+\left(1-\alpha_{2}\right)\left(y_{2}^{0}\left(t_{2}\right)-a_{2}\right)\right)$,

taking $\left\{t_{2}, a_{2}\right\}$ as given. Similarly, country 2 chooses $\left\{t_{2}, a_{2}\right\}$ to maximize

$W_{2}\left(t_{1}, t_{2}, a_{1}, a_{2}\right)=x_{2}^{0}\left(t_{2}, a_{2}\right)+u\left(y_{2}^{0}\left(t_{2}\right)\right)-v\left(\left(1-\alpha_{1}\right)\left(y_{1}^{0}\left(t_{1}\right)-a_{1}\right)+\alpha_{2}\left(y_{2}^{0}\left(t_{2}\right)-a_{2}\right)\right), \quad$ (Eq.8b)

taking as given $\left\{t_{1}, a_{1}\right\}$. In equations (8a) and (8b), $\left(1-\alpha_{2}\right)\left(y_{2}^{0}\left(t_{2}\right)-a_{2}\right)$ and $\left(1-\alpha_{1}\right)\left(y_{1}^{0}\left(t_{1}\right)-a_{1}\right)$ are the transboundary externality components.

The first order interior conditions for the problem faced by country 1 are:

$$
\begin{gathered}
\frac{\partial x_{1}^{0}}{\partial t_{1}}+\left(u^{\prime}\left(y_{1}^{0}\right)-\alpha_{1} v^{\prime}\left(D_{1}\right)\right)\left(\frac{\partial y_{1}^{0}}{\partial t_{1}}\right)=0, \\
\frac{\partial x_{1}^{0}}{\partial a_{1}}+\alpha_{1} v^{\prime}\left(D_{1}\right)=0 .
\end{gathered}
$$

By substituting equations (5) - (7) into the above equations, we can express them as:

$$
\begin{gathered}
-p \frac{\partial y_{1}^{0}}{\partial t_{1}}+\left(p+t_{1}-\alpha_{1} v^{\prime}\left(D_{1}\right)\right)\left(\frac{\partial y_{1}^{0}}{\partial t_{1}}\right)=0 \\
-s+\alpha_{1} v^{\prime}\left(D_{1}\right)=0
\end{gathered}
$$

which leads to:

$$
\begin{aligned}
& t_{1}=\alpha_{1} v^{\prime}\left(D_{1}\right), \\
& \alpha_{1} v^{\prime}\left(D_{1}\right)=s .
\end{aligned}
$$

The first order interior conditions for the problem faced by country 2 similarly result in:

$$
t_{2}=\alpha_{2} v^{\prime}\left(D_{2}\right)
$$




$$
\alpha_{2} v^{\prime}\left(D_{2}\right)=s
$$

From equation (9) we see that country 1 sets its pollution tax equal to the marginal damage incurred solely from the salination level within its own boundary. Equation (10) demonstrates that country 1 produces abatement up to the level that equates marginal benefit and cost from abatement. The marginal benefit from abatement corresponds to the marginal salination damage avoided due to the country's production of an extra unit of abatement. Equations (11) and (12) are the anologues of equations (9) and (10), respectively, for country 2 .

Since the noncooperative water allocation is a Nash equlibrium, we use the superscript " $N$ " to denote our key noncooperative results. From equations (9) - (12) we obtain $t_{1}=\alpha_{1} v^{\prime}\left(D_{1}\right)=s$ and $t_{2}=\alpha_{2} v^{\prime}\left(D_{2}\right)=s$, which lead to:

$$
t_{1}^{N}=t_{2}^{N}=s .
$$

Combining equations (13) with (5), and recalling our curvature assumptions on $u(\cdot)$ yields

$$
y_{1}^{N}=y_{2}^{N}=y^{N}
$$

In addition, equations (10) and (12), result in $\alpha_{1} v^{\prime}\left(D_{1}\right)=\alpha_{2} v^{\prime}\left(D_{2}\right)$, which, given our curvature assumptions on $v(\cdot)$, lead to:

$$
\alpha_{1} \leq \alpha_{2} \Rightarrow\left\{\begin{array}{l}
D_{1}^{N}>D_{2}^{N} \\
D_{1}^{N}=D_{2}^{N} \\
D_{1}^{N}<D_{2}^{N}
\end{array}\right.
$$

To see this result, note that $\alpha_{1} v^{\prime}\left(D_{1}\right)=\alpha_{2} v^{\prime}\left(D_{2}\right)$ can be written as $\frac{v^{\prime}\left(D_{1}\right)}{v^{\prime}\left(D_{2}\right)}=\frac{\alpha_{2}}{\alpha_{1}}$. From this equality and the assumption that $v^{\prime \prime}>0$, the following result is immediate:

$$
\begin{aligned}
& \alpha_{1}>\alpha_{2} \Rightarrow v^{\prime}\left(D_{2}^{N}\right)>v^{\prime}\left(D_{1}^{N}\right) \Rightarrow D_{1}^{N}<D_{2}^{N} \\
& \alpha_{1}=\alpha_{2} \Rightarrow v^{\prime}\left(D_{2}^{N}\right)=v^{\prime}\left(D_{1}^{N}\right) \Rightarrow D_{1}^{N}=D_{2}^{N} \\
& \alpha_{1}<\alpha_{2} \Rightarrow v^{\prime}\left(D_{2}^{N}\right)<v^{\prime}\left(D_{1}^{N}\right) \Rightarrow D_{1}^{N}>D_{2}^{N}
\end{aligned}
$$

Above result tells us that a country's water withdrawal affects more the level of salination of a neighbor country than that of itself in the Nash equilibrium. We can see for example in the first inequality that country 2 will incur greater level of damage from salination than country 1 when the fraction of emitted salt dust in country 1 is higher than that in country 2 . 


\section{Fully cooperative salination benchmark}

Next we consider a fully cooperative water allocation. To obtain this allocation, we assume a central government, or benevolent social planner, takes into consideration the aggregate economic benefits of the lake basin countries. In this regard, the central government chooses $\left\{a_{i}, t_{i}\right\}_{i=1,2}$ to maximize the aggregate sum of the two counties' welfares:

$$
\begin{gathered}
W_{1}\left(t_{1}, t_{2}, a_{1}, a_{2}\right)+W_{2}\left(t_{1}, t_{2}, a_{1}, a_{2}\right) \\
x_{1}^{0}\left(t_{1}, a_{1}\right)+u\left(y_{1}^{0}\left(t_{1}\right)\right)-v\left(\alpha_{1}\left(y_{1}^{0}\left(t_{1}\right)-a_{1}\right)+\left(1-\alpha_{2}\right)\left(y_{2}^{0}\left(t_{2}\right)-a_{2}\right)\right)+ \\
x_{2}^{0}\left(t_{2}, a_{2}\right)+u\left(y_{2}^{0}\left(t_{2}\right)\right)-v\left(\left(1-\alpha_{1}\right)\left(y_{1}^{0}\left(t_{1}\right)-a_{1}\right)+\alpha_{2}\left(y_{2}^{0}\left(t_{2}\right)-a_{2}\right)\right) .
\end{gathered}
$$

First-order conditions are:

$$
\begin{gathered}
\frac{\partial x_{1}^{0}}{\partial t_{1}}+\left(u^{\prime}\left(y_{1}^{0}\right)-\alpha_{1} v^{\prime}\left(D_{1}\right)-\left(1-\alpha_{1}\right) v^{\prime}\left(D_{2}\right)\right)\left(\frac{\partial y_{1}^{0}}{\partial t_{1}}\right)=0 \\
\frac{\partial x_{2}^{0}}{\partial t_{2}}+\left(u^{\prime}\left(y_{2}^{0}\right)-\left(1-\alpha_{2}\right) v^{\prime}\left(D_{1}\right)-\alpha_{2} v^{\prime}\left(D_{2}\right)\right)\left(\frac{\partial y_{2}^{0}}{\partial t_{2}}\right)=0 \\
\frac{\partial x_{1}^{0}}{\partial a_{1}}+\alpha_{1} v^{\prime}\left(D_{1}\right)+\left(1-\alpha_{1}\right) v^{\prime}\left(D_{2}\right)=0 \\
\frac{\partial x_{2}^{0}}{\partial a_{2}}+\left(1-\alpha_{2}\right) v^{\prime}\left(D_{1}\right)+\alpha_{2} v^{\prime}\left(D_{2}\right)=0
\end{gathered}
$$

Similar to the derivation of equations (9) - (15), using equations (5) - (7), we obtain $t_{1}=\alpha_{1} v^{\prime}\left(D_{1}\right)+\left(1-\alpha_{1}\right) v^{\prime}\left(D_{2}\right)=s$ and $t_{2}=\left(1-\alpha_{2}\right) v^{\prime}\left(D_{1}\right)+\alpha_{2} v^{\prime}\left(D_{2}\right)=s$. We denote the cooperative allocation conditions by the superscript "*” that result in:

$$
\begin{aligned}
t_{1}^{*} & =t_{2}^{*}=s, \\
\alpha_{1} v^{\prime}\left(D_{1}^{*}\right)+\left(1-\alpha_{1}\right) v^{\prime}\left(D_{2}^{*}\right) & =\left(1-\alpha_{2}\right) v^{\prime}\left(D_{1}^{*}\right)+\alpha_{2} v^{\prime}\left(D_{2}^{*}\right)=s .
\end{aligned}
$$

Equation (17) parallels equation (13) from the noncooperative equilibrium. Similarly (18) parallels to (10) and (12). As in the noncooperative equilibrium, (5) can again be used to show:

$$
y_{1}^{*}=y_{2}^{*}=y^{*} .
$$

As a consequence of the equalization of marginal social damages in (18), total damages equate as well. To see this, note from the first equality in (18) that $\left(1-\alpha_{1}-\alpha_{2}\right) v^{\prime}\left(D_{1}^{*}\right)=\left(1-\alpha_{1}-\alpha_{2}\right) v^{\prime}\left(D_{2}^{*}\right)$, which implies

$$
D_{1}^{*}=D_{2}^{*}=D^{*}
$$

In other words, unlike in the Nash equilibrium, where the relative signs of $D_{1}$ and $D_{2}$ depend on the sizes of $\alpha_{1}$ and $\alpha_{2}$, the socially efficient damages equate irrespective of the values of $\alpha_{1}$ and $\alpha_{2}$. 
The following proposition compares the Nash Equilibrium with the cooperative solution.

Proposition 1. The comparison between noncooperative and cooperative allocations reveals that

$$
D_{1}^{N}>D_{1}^{*}, \quad D_{2}^{N}>D_{2}^{*}, \quad E_{1}^{N}+E_{2}^{N}=E^{N}>E^{*}=E_{1}^{*}+E_{2}^{*}, \quad y^{N}=y^{*},
$$

$a_{1}^{N}+a_{2}^{N}=a^{N}<a^{*}=a_{1}^{*}+a_{2}^{*}$.

Proof: Comparing equations (13) and (17), we see that $t_{i}^{N}=t_{i}^{*}, i=1,2$. Thus, equations (14) and (19) imply that $y^{N}=y^{*}$ for given $p$. Given (20) and $\alpha_{2}<1$, comparing the second equality in (18) with (12) yields $v^{\prime}\left(D_{2}^{*}\right)=s=\alpha_{2} v^{\prime}\left(D_{2}^{N}\right) \Rightarrow$ $D_{2}^{N}>D_{2}^{*}$. Similarly, comparing the first equality in (18) with (10) yields $v^{\prime}\left(D_{1}^{*}\right)=s=\alpha_{1} v^{\prime}\left(D_{1}^{N}\right) \Rightarrow D_{1}^{N}>D_{1}^{*}$. The inequalities $D_{i}^{N}>D_{i}^{*}, i=1,2$, in turn imply the following two inequalities: $\alpha_{1}\left(y_{1}^{N}-a_{1}^{N}\right)+\left(1-\alpha_{2}\right)\left(y_{2}^{N}-a_{2}^{N}\right)>\alpha_{1}\left(y_{1}^{*}-a_{1}^{*}\right)+\left(1-\alpha_{2}\right)\left(y_{2}^{*}-a_{2}^{*}\right) \quad$ and $\left(1-\alpha_{1}\right)\left(y_{1}^{N}-a_{1}^{N}\right)+\alpha_{2}\left(y_{2}^{N}-a_{2}^{N}\right)>\left(1-\alpha_{1}\right)\left(y_{1}^{*}-a_{1}^{*}\right)+\alpha_{2}\left(y_{2}^{*}-a_{2}^{*}\right)$.

Adding these two inequalities results in $\left(y_{1}^{N}-a_{1}^{N}\right)+\left(y_{2}^{N}-a_{2}^{N}\right)>\left(y_{1}^{*}-a_{1}^{*}\right)+\left(y_{2}^{*}-a_{2}^{*}\right)$, i.e. $E_{1}^{N}+E_{2}^{N}=E^{N}>E^{*}=E_{1}^{*}+E_{2}^{*}$. The result $y^{N}=y^{*}$ then implies that $a_{1}^{N}+a_{2}^{N}=a^{N}<a^{*}=a_{1}^{*}+a_{2}^{*}$.

As expected, Proposition 1 shows that lake basin countries produce too little pollution abatement in the Nash Equilibrium and consequently generate too much salination relative to the respective socially efficient levels. Interestingly, in the Nash Equilibrium the two countries set efficient tax rates, which in turn yield socially efficient withdrawal levels. These results indicate that in a partially cooperative regime, where the national governments share authority with a central government, it is necessary to give abatement authority to the central government, while allowing the national governments to retain authority over pollution taxes. We explore this sharing arrangement in the next section, with the added condition that the national governments set their tax rates prior to the central government's choice of abatement levels. This scheme is called "Decentralized Leadership".

\section{Decentralized leadership game}

Following Caplan and Silva (1999), we examine a Stackelberg Equilibrium, whereby the national governments choose their respective tax rates before a central government chooses their abatement levels. Their arrangement presumes that countries 1 and 2 have integrated into a union with the central government. The central and national governments have agreed beforehand to form the union. Under the decentralized leadership framework, the national governments act as Stackelberg leaders and the central government as a Stackelberg follower. Fig. 1 depicts their arrangement. 


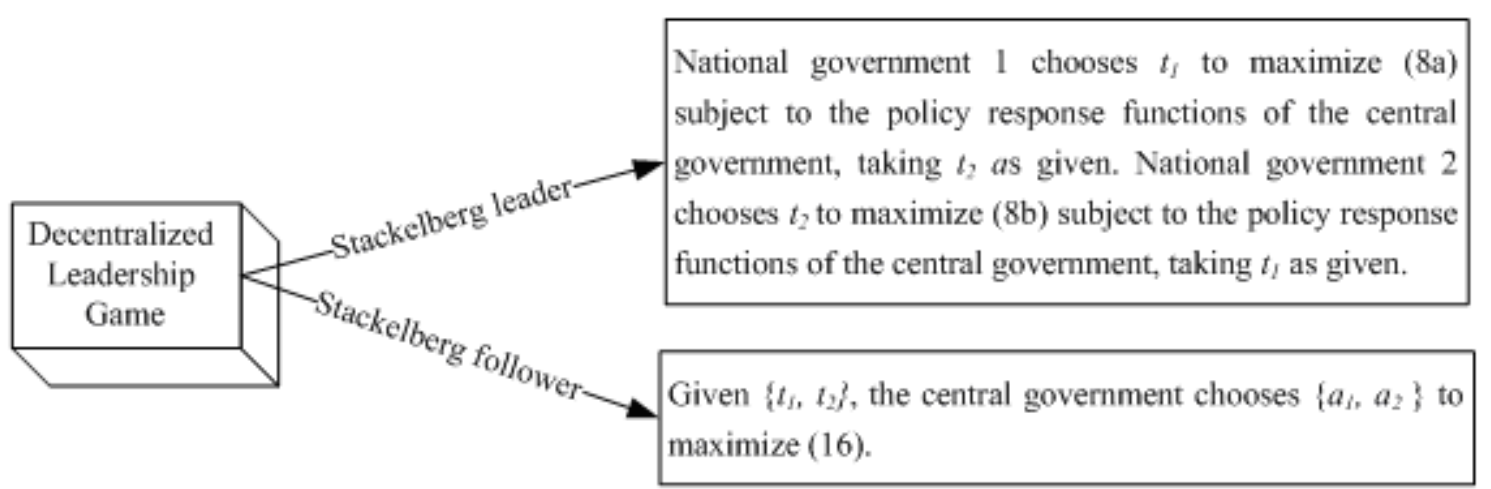

Figure 1 The Decentralized Leadership Game

We solve for this game's subgame perfect equilibrium by backward induction, therefore starting with the central government's choice of $\left\{a_{1}, a_{2}\right\}$ to maximize (16), taking $\left\{t_{1}, t_{2}\right\}$ as given.

Noting equations (1) and (7), this problem yields the following first order conditions:

$$
\begin{aligned}
& \alpha_{1} v^{\prime}\left(D_{1}\right)+\left(1-\alpha_{1}\right) v^{\prime}\left(D_{2}\right)=s, \\
& \left(1-\alpha_{2}\right) v^{\prime}\left(D_{1}\right)+\alpha_{2} v^{\prime}\left(D_{2}\right)=s .
\end{aligned}
$$

Via comparison with equation (18), equations (21) and (22) show that the equilibrium salination damages in this game, $D_{1}^{1}$ and $D_{2}^{1}$, are both equal to $D^{*}$. In other words, when endowed with the authority to set abatement levels in the final stage of a two-stage game with the national governments, the central government has no other incentive than to follow its optimal abatement rule. Defining the abatement levels as implicit functions of $t_{1}$ and $t_{2}$, i.e. $a_{i}^{1}\left(t_{1}, t_{2}\right)^{1}, i=1,2$, we can now specify the central government's abatement responses by first differentiating equations (21) and (22) with respect to $t_{1}$, which yields

$$
\begin{aligned}
& \alpha_{1} v^{\prime \prime}\left(D_{1}\right)\left(\alpha_{1}\left(\frac{\partial y_{1}^{0}}{\partial t_{1}}-\frac{\partial a_{1}^{1}}{\partial t_{1}}\right)-\left(1-\alpha_{2}\right) \frac{\partial a_{2}^{1}}{\partial t_{1}}\right)+\left(1-\alpha_{1}\right) v^{\prime \prime}\left(D_{2}\right)\left(\left(1-\alpha_{1}\right)\left(\frac{\partial y_{1}^{0}}{\partial t_{1}}-\frac{\partial a_{1}^{1}}{\partial t_{1}}\right)-\alpha_{2} \frac{\partial a_{2}^{1}}{\partial t_{1}}\right)=0, \\
& \left(1-\alpha_{2}\right) v^{\prime \prime}\left(D_{1}\right)\left(\alpha_{1}\left(\frac{\partial y_{1}^{0}}{\partial t_{1}}-\frac{\partial a_{1}^{1}}{\partial t_{1}}\right)-\left(1-\alpha_{2}\right) \frac{\partial a_{2}^{1}}{\partial t_{1}}\right)+\alpha_{2} v^{\prime \prime}\left(D_{2}\right)\left(\left(1-\alpha_{1}\right)\left(\frac{\partial y_{1}^{0}}{\partial t_{1}}-\frac{\partial a_{1}^{1}}{\partial t_{1}}\right)-\alpha_{2} \frac{\partial a_{2}^{1}}{\partial t_{1}}\right)=0
\end{aligned}
$$

Since $D_{1}^{1}=D_{2}^{1}=D^{*}$ and $v^{\prime \prime}>0$, we can rewrite equations (23a) and (23b) as follows:

$$
\alpha_{1}\left(\alpha_{1}\left(\frac{\partial y_{1}^{0}}{\partial t_{1}}-\frac{\partial a_{1}^{1}}{\partial t_{1}}\right)-\left(1-\alpha_{2}\right) \frac{\partial a_{2}^{1}}{\partial t_{1}}\right)+\left(1-\alpha_{1}\right)\left(\left(1-\alpha_{1}\right)\left(\frac{\partial y_{1}^{0}}{\partial t_{1}}-\frac{\partial a_{1}^{1}}{\partial t_{1}}\right)-\alpha_{2} \frac{\partial a_{2}^{1}}{\partial t_{1}}\right)=0
$$

\footnotetext{
${ }^{1}$ We use superscript "1" to denote equilibrium quantities in this game.
} 


$$
\left(1-\alpha_{2}\right)\left(\alpha_{1}\left(\frac{\partial y_{1}^{0}}{\partial t_{1}}-\frac{\partial a_{1}^{1}}{\partial t_{1}}\right)-\left(1-\alpha_{2}\right) \frac{\partial a_{2}^{1}}{\partial t_{1}}\right)+\alpha_{2}\left(\left(1-\alpha_{1}\right)\left(\frac{\partial y_{1}^{0}}{\partial t_{1}}-\frac{\partial a_{1}^{1}}{\partial t_{1}}\right)-\alpha_{2} \frac{\partial a_{2}^{1}}{\partial t_{1}}\right)=0
$$

Solving the above equations simultaneously, yields

$$
\frac{\partial y_{1}^{0}}{\partial t_{1}}-\frac{\partial a_{1}^{1}}{\partial t_{1}}=\frac{\partial a_{2}^{1}}{\partial t_{1}}=0
$$

for $\alpha_{1}+\alpha_{2} \neq 1^{2}$.

Similarly, differentiation of equations (21) and (22) with respect to $t_{2}$ and simultaneous solution yields

$$
\frac{\partial y_{2}^{0}}{\partial t_{2}}-\frac{\partial a_{2}^{1}}{\partial t_{2}}=\frac{\partial a_{1}^{1}}{\partial t_{2}}=0
$$

for $\alpha_{1}+\alpha_{2} \neq 1$

From (Eq.24) and (Eq.25), we can write $a_{i}^{1}=a_{i}^{1}\left(t_{i}\right), i=1,2$. We also see that the central government responds to changes in each country's pollution tax by choosing abatement such that salination remains at its socially efficient level in each country.

As a Stackelberg leader, national government 1 chooses $t_{1}$ to maximize (Eq.8a) subject to $a_{1}^{1}=a_{1}^{1}\left(t_{1}\right)$ derived in (Eq.24). Similarly, national government 2 chooses $t_{2}$ to maximize (Eq.8b) subject to $a_{2}^{1}=a_{2}^{1}\left(t_{2}\right)$ derived in (Eq.25). Using (Eq.6), (Eq.7), and (Eq.24) and (Eq.25) respectively, we find that the first - order conditions characterizing the Nash equilibrium in the second - stage of the game reduces to:

$$
u^{\prime}\left(y_{i}\right)=p+s, \quad i=1,2
$$

Combining equations (26) with (5), and recalling (21) and (22), we see that the subgame perfect equilibrium for Game 1 satisfies the fully cooperative allocation conditions (17) and (18). These cooperative allocation conditions describe the Nash equilibrium tax rates in stage 1 of the decentralized - leadership game:

$$
\begin{aligned}
& t_{1}^{1}=t_{1}^{*}=\alpha_{1} v^{\prime}\left(D_{1}^{*}\right)+\left(1-\alpha_{1}\right) v^{\prime}\left(D_{2}^{*}\right) \\
& t_{2}^{1}=t_{2}^{*}=\left(1-\alpha_{2}\right) v^{\prime}\left(D_{1}^{*}\right)+\alpha_{2} v^{\prime}\left(D_{2}^{*}\right)
\end{aligned}
$$

Equations (27a) and (27b) demonstrate that the national governments choose to set their respective pollution tax rates equal to the marginal social damage caused by their country's water withdrawal level. Their result is driven by the national governments' anticipation of the central government's pollution abatement policy response to their respective pollution tax policies. If a national government sets the pollution tax too low (relative to the socially efficient rate), thereby encouraging excessive water use for

\footnotetext{
${ }^{2}$ This stage of the game does not admit a definite solution for the case of $\alpha_{1}+\alpha_{2}=1$
} 
irrigation, the central government responds with an abatement level that offsets the expansionary effect of the low tax on the irrigation level generated in the basin. Correspondingly, if the national government sets the pollution tax too high, the central government will offset with reduced abatement for this country in order to maintain that country's salination at the socially efficient level. This leads to our second and final proposition.

Proposition 2. The subgame perfect equilibrium for Game 1 is a socially optimal.

Proof: Equations (21) and (22) are identical to (18). Equations (17) are implied by equations (5) and (26).

\section{Conclusion}

Our analysis suggests that a partially cooperative water withdrawal agreement between countries that share a lake basin used for cotton irrigation can reduce the level of salination to its socially efficient level. Our findings show that under an agreement where a central government sets a salination abatement levels after the national governments impose taxes an irrigation, the socially efficient level of salination can be attained. Both policy instruments - abatement and the tax - do not need to be controlled by a central authority.

In this paper we do not investigate the other three Stackelberg Equilibrium games that Caplan and Silva (1999) examine. If we analyzed them, we would expect results similar to Caplan and Silva (1999) for acid rain in an upstream - downstream setting. Particularly, we would see that the central government is unable to respond completely to the national governments' abatement policies by their pollution taxes in the second subgame of the decentralized leadership. The pollution tax rates would be higher in the second subgame equilibrium than tax rates in the first subgame equilibrium that we have studied.

In the centralized leadership subgames, where the central government acts as a Stackelberg leader and the national governments act as Stackelberg followers, we could see that the national governments are ignoring to follow the central government's policies. The results would demonstrate that country did not recognize the salination damage that its water withdrawal caused in the neighbor country. Consequently, basin's countries would not obtain the social efficient salination levels.

Finally, we hope that our findings should enable local and central policymakers to better assess the implication of cooperative water withdrawing practices in international river and lake basins. As we have shown in this paper, a Pareto optimal allocation can be attained through partial cooperation.

\section{REFERENCES}

[1] Cotton This Week, International Cotton Advisory Committee, February 2005.

[2] Gillham, F. et al. (1995): Cotton Production Prospects for the Next Decade, World Bank Technical Paper Number 287. - The World Bank, Washington D.C.

[3] Godwin, O., Obasi, P. (2003): Challenges and Opportunities in Water Resource Management. - World Meteorological Organization (Lecture at the 93rd Annual Meeting of the American Meteorological Society, February 11, 2003). 
[4] Hardin, G. (1968): The Tragedy of the Commons. - Science 162: 1243-1248.

[5] ICG (2002): Central Asia: Water and Conflict. - ICG Asia Report N34, Brussels.

[6] Mangold, T., Goldberg, J. (2001): Plague Wars: The Terrifying Reality of Biological Warfare. - Macmillan, pp.46-47, ISBN 9780312263799.

[7] Micklin, P., Aladin, N.V. (2008): Reclaiming the Aral Sea. - Scientific American 3.

[8] Moulin, H. (1995): Cooperative Microeconomics: a Game - Theoretic Introduction. Princeton University Press, Princeton.

[9] Rogers, P. (1969): A Game Theory Appoach to the Problems of International River Basins. - Water Resources Res 5(4): 749-760.

[10] Silva, E.C.D., Caplan, A. (1999): Federal Acid Rain Games. - Journal of Urban Economics 46: 25-52.

[11] UNESCO (2000): Water Related Vision for the Aral Sea Basin for the Year 2025. Paris.

[12] Willis, T.M., Black, A.S. (1996): Irrigation Increases Groundwater Recharge in the Macquairie Valley. - Australian Journal of Soil Research 34(6): 837-847.

[13] WRI (2000): World Resources 2000-2001: People and Ecosystems: the Fraying Web of Life. - World Resources Institute, Washington, D.C.

[14] Zilberman, D. (1998): The Impact of Agriculture on Water Quality. - In: OECD: Sustainable Management of Water in Agriculture: Issues and Policies, Paris, p.133-149. 